\title{
Comparative Analysis of T Cell Imaging with Human Nuclear Reporter Genes
}

\author{
Maxim A. Moroz ${ }^{1}$, Hanwen Zhang ${ }^{1}$, Jason Lee ${ }^{2}$, Ekaterina Moroz ${ }^{3}$, Juan Zurita ${ }^{1}$, Larissa Shenker ${ }^{1}$, Inna Serganova ${ }^{3}$, \\ Ronald Blasberg ${ }^{1,3,4}$, and Vladimir Ponomarev ${ }^{1,4}$ \\ ${ }^{1}$ Department of Radiology, Memorial Sloan Kettering Cancer Center, New York, New York; ${ }^{2}$ Crump Institute for Molecular Imaging, \\ University of California, Los Angeles, California; ${ }^{3}$ Department of Neurology, Memorial Sloan Kettering Cancer Center, New York, \\ New York; and ${ }^{4}$ Sloan Kettering Institute Molecular Pharmacology and Chemistry Program, Memorial Sloan Kettering Cancer \\ Center, New York, New York
}

Monitoring genetically altered T cells is an important component of adoptive $\mathrm{T}$ cell therapy in patients, and the ability to visualize their trafficking/targeting, proliferation/expansion, and retention/death using highly sensitive reporter systems that do not induce an immunologic response would provide useful information. Therefore, we focused on human reporter gene systems that have the potential for translation to clinical studies. The objective of the in vivo imaging studies was to determine the minimum number of $T$ cells that could be visualized with the different nuclear reporter systems. We determined the imaging sensitivity (lower limit of $T$ cell detection) of each reporter using appropriate radiolabeled probes for PET or SPECT imaging. Methods: Human T cells were transduced with retroviral vectors encoding for the human norepinephrine transporter (hNET), human sodium-iodide symporter (hNIS), a human deoxycytidine kinase double mutant (hdCKDM), and herpes simplex virus type 1 thymidine kinase (hsvTK) reporter genes. After viability and growth were assessed, $10^{5}$ to $3 \times 10^{6}$ reporter $\mathrm{T}$ cells were injected subcutaneously on the shoulder area. The corresponding radiolabeled probe was injected intravenously 30 min later, followed by sequential PET or SPECT imaging. Radioactivity at the $T$ cell injection sites and in the thigh (background) was measured. Results: The viability and growth of experimental cells were unaffected by transduction. The hNET/ meta- ${ }^{18} \mathrm{~F}$-fluorobenzylguanidine (18 $\mathrm{F}-\mathrm{MFBG}$ ) reporter system could detect less than $1 \times 10^{5} \mathrm{~T}$ cells because of its high uptake in the transduced $\mathrm{T}$ cells and low background activity. The $h N / S /{ }^{124} \mathrm{I}-$ iodide reporter system could detect approximately $1 \times 10^{6} \mathrm{~T}$ cells; ${ }^{124}$ I-iodide uptake at the $\mathrm{T}$ cell injection site was time-dependent and associated with high background. The $h d C K D M / 2^{\prime}-{ }^{18} \mathrm{~F}$-fluoro5 -ethyl-1- $\beta$-D-arabinofuranosyluracil $\left({ }^{18} \mathrm{~F}-\mathrm{FEAU}\right)$ and $h s v T K /{ }^{18} \mathrm{~F}-$ FEAU reporter systems detected approximately $3 \times 10^{5} \mathrm{~T}$ cells, respectively. ${ }^{18} \mathrm{~F}-\mathrm{FEAU}$ was a more efficient probe (higher uptake, lower background) than 124l-1-(2-deoxy-2-fluoro-1-D-arabinofuranosyl)-5-iodouracil for both hdCKDM and hsvTK. Conclusion: A comparison of different reporter gene-reporter probe systems for imaging of $\mathrm{T}$ cell number was performed, and the $h N E T /{ }^{18} \mathrm{~F}-\mathrm{MFBG}$ PET reporter system was found to be the most sensitive and capable of detecting approximately $35-40 \times 10^{3} \mathrm{~T}$ cells at the site of $\mathrm{T}$ cell injection in the animal model.

Received Apr. 23, 2015; revision accepted Apr. 25, 2015.

For correspondence or reprints contact: Vladimir Ponomarev, Molecular Imaging Laboratory, Department of Radiology, Memorial Sloan Kettering Cancer Center, 1275 York Ave. (Box 501) Z-2063, New York, NY 10021.

E-mail:ponomarv@mskcc.org

Published online May 29, 2015.

COPYRIGHT (C 2015 by the Society of Nuclear Medicine and Molecular Imaging, Inc.
Key Words: T cells; imaging; PET; reporter genes

J Nucl Med 2015; 56:1055-1060

DOI: 10.2967/jnumed.115.159855

A is a promising and rapidly evolving field. Further advances in the field of adoptive therapy will require the ability to monitor the trafficking, targeting, and activation/proliferation of the administered cells. The application of novel reporter systems (gene-probe combinations) together with noninvasive imaging modalities, such as PET, has shown the potential for monitoring T cells in vivo (1-4). Herpes simplex virus type 1 thymidine kinase (hsvTK) and mutant hsv1sr39TK reporter genes have been used in most of these seminal studies. Radiolabeled reporter probes, including 1-(2-deoxy-2-fluoro1-D-arabinofuranosyl)-5-iodouracil (FIAU) (labeled with ${ }^{131} \mathrm{I}$ (5), ${ }^{123} \mathrm{I}(5),{ }^{124} \mathrm{I}(6)$, and $\left.{ }^{125} \mathrm{I}(7)\right), 2^{2}$ - ${ }^{18} \mathrm{~F}$-fluoro-5-ethyl-1- $\beta$-D-arabinofuranosyluracil ( $\left.{ }^{18} \mathrm{~F}-\mathrm{FEAU}\right)(8)$, and $9-\left(4-{ }^{18} \mathrm{~F}-\right.$ fluoro-3-[hydroxymethyl] butyl)guanine ( $\left.{ }^{18} \mathrm{~F}-\mathrm{FHBG}\right)(9)$ have been used for imaging hsvTK in these studies, and comparisons of their efficacy have previously been performed (10-12). However, there has been a recent focus on human reporter systems, to avoid the potential risk of generating an immunologic reaction to viral (nonhuman) reporter systems, including hsvTK and hsvsr39TK reporter-transduced T cells.

We and others have tested different human-derived reporter systems for potential cell tracking in patients (12-21). These intrinsically nonimmunogenic reporter systems include the human sodium iodide symporter $(h N I S) /{ }^{124}$ I-iodide (13), the human norepinephrine transporter $\left(\right.$ hNET) $/{ }^{123} \mathrm{I} /{ }^{124} \mathrm{I}$-metaiodobenzylguanidine (MIBG) (14) and ${ }^{18} \mathrm{~F}$-meta- ${ }^{18} \mathrm{~F}$-fluorobenzylguanidine $\left({ }^{18} \mathrm{~F}-\mathrm{MFBG}\right)(15)$, the human somatostatin receptor $2\left(\right.$ SSTR $2 /{ }^{68} \mathrm{Ga}$-DOTATOC) $(16,17)$, the human ferritin ${ }^{2+} \mathrm{Fe}$ reporter (18), and the human transferrin receptor (19). More recently described reporter genes include the truncated and mutated human mitochondrial thymidine kinase type 2 (h $\Delta \mathrm{TK} 2$, $\mathrm{h} \Delta \mathrm{TK} 2 \mathrm{DM})$ genes $(20,21)$ and the mutated human deoxycytidine kinase (hdCKDM) gene (22-24). Both human kinases were shown to exclusively phosphorylate pyrimidine-based PET probes, including ${ }^{124}$ I-FIAU, ${ }^{18} \mathrm{~F}-\mathrm{FEAU}$, and 2 '-deoxy-2' - ${ }^{18}$ F-fluoro-5-methyl-1$\beta$-L-arabinofuranosyluracil.

The objective of this report was to compare the $\mathrm{T}$ cell imaging efficacy of 1 viral and 3 human reporter genes with different imaging probes (different reporter systems). We compared the $h N E T /{ }^{18} \mathrm{~F}$ MFBG and ${ }^{123} \mathrm{I} /{ }^{124} \mathrm{I}-\mathrm{MIBG}$ reporter systems with the previously 
described hNIS, hdCKDM, and hsvTK reporter systems using radiolabeled ${ }^{124}$ I-iodide, ${ }^{18} \mathrm{~F}$-FEAU, and ${ }^{124} \mathrm{I}$-FIAU, respectively. We included ${ }^{18} \mathrm{~F}-\mathrm{MFBG}$ as an alternative to ${ }^{123} \mathrm{I} /{ }^{124} \mathrm{I}-\mathrm{MIBG}$, for imaging hNET reporter-transduced $\mathrm{T}$ cells, because of the superior tumor-tobackground images that can be obtained at earlier times after administration of MFBG compared with MIBG $(15,25)$. Using a murine preclinical model, we determined the minimum number of reporter-transduced $\mathrm{T}$ cells that could be imaged with the different reporter systems. Our results demonstrate that the $h N E T /{ }^{18} \mathrm{~F}-\mathrm{MFBG}$ reporter system is the most sensitive and allows for repetitive PET imaging of hNET-expressing T cells.

\section{MATERIALS AND METHODS}

\section{Development of New Retroviral Vectors}

Two new retroviral vectors, which carry the constitutively expressed hNET or hNIS separated by IRES (internal ribosomal entry site) with green fluorescent protein (GFP), were developed by recloning of the hNET (14) and hNIS (14) genes into the retroviral SFG backbone. The hsvTK/GFP and hdCKDM/GFP vectors were developed previously (Supplemental Fig. 1; supplemental materials are available at http://jnm. snmjournals.org) $(13,26)$. The hsvTK-IRES-GFP and hdCKDM-IRESGFP dual reporters were subsequently developed to compare the transduced-to-nontransduced T cell uptake ratio of the fusion and IRES-linked reporter systems for both hsvTK and hdCKDM (Supplemental Fig. 2).

\section{T Cell Isolation, Transduction, Assessment, and Expansion}

Buffy coat-containing $\mathrm{T}$ cells $(60 \mathrm{~mL})$ were obtained from the New York Blood Bank from healthy donors, who gave informed consent. T cells were isolated using Ficoll isolation medium as previously described (27). At $48 \mathrm{~h}$ after stimulation with phytohemagglutinin at a concentration of $2 \mu \mathrm{g} / \mathrm{mL}$, T cells were transduced with a reporter gene-bearing retrovirus in the presence of interleukin-2 $(20 \mathrm{U} / \mathrm{mL})$, as described previously (4). During T cell expansion, the medium was supplemented with IL-15 at a concentration of $10 \mathrm{ng} / \mathrm{mL}$ every $3 \mathrm{~d}$. T cell viability was measured using trypan blue exclusion. Analysis of GFP expression in all experimental cell populations was performed using a FACSCalibur analyzer (BD Biosciences), and the purity and fluorescence of cells were assessed using Cell Quest Software (Becton Dickinson). All assays were repeated at least 3 times.

\section{Reporter T Cell Studies: In Vitro Uptake of Radiolabeled Probes}

The radiolabeled imaging probes were prepared as previously described. ${ }^{18} \mathrm{~F}-\mathrm{MFBG}(\sim 19 \mathrm{GBq} / \mu \mathrm{mol})(15),{ }^{18} \mathrm{~F}-\mathrm{FEAU}(\sim 22 \mathrm{GBq} / \mu \mathrm{mol})$ (28), carrier-free ${ }^{124} \mathrm{I}-\mathrm{MIBG}(>12 \mathrm{GBq} / \mu \mathrm{mol})$, carrier-free ${ }^{124} \mathrm{I}$-iodide, and carrier-free ${ }^{124}$ I-FIAU were synthesized at Memorial Sloan Kettering Cancer Center (28). ${ }^{123}$ I-MIBG (clinical formulation) was obtained from Nuclear Diagnostics Products.

Triplicate samples containing $1.0 \times 10^{6}$ reporter-transduced or wildtype $\mathrm{T}$ cells in a total volume of $1.0 \mathrm{~mL}$ were incubated in RMPI medium containing fetal calf serum $(10 \%)$ with $18.5 \mathrm{kBq} / \mathrm{mL}$ $(0.5 \mu \mathrm{Ci} / \mathrm{mL})$ of each specific probe. The samples were gently shaken at $37^{\circ} \mathrm{C}$ for $2 \mathrm{~h}$. After incubation, the cells were isolated by rapid filtration through glass microfiber filters and washed with $3 \times 2 \mathrm{~mL}$ of ice-cold Tris-buffered saline ( $\mathrm{pH}$ 7.4). The radioactivity in cells was measured with a $\gamma$-Packard $\gamma$ counter (United Technologies).

\section{Xenotransplantation of T Cells}

All animal studies were performed under a Memorial Sloan Kettering Cancer Center protocol approved by the Institutional Animal Care and Use Committee. Athymic rnu/rnu male mice were obtained from the National Cancer Institute; the mice were 3 mo old at the time of the imaging. The mice were anesthetized by inhalation of isoflurane/oxygen and maintained on a heating pad. After completion of the imaging studies, all animals were sacrificed by $\mathrm{CO}_{2}$ inhalation.

$\mathrm{T}$ cells were prepared in fresh batches for each cohort of animals and assessed for viability before every set of injections. Every batch of $\mathrm{T}$ cells was normalized for transduction efficacy and percentage live cells and diluted in $50 \mu \mathrm{L}$ of $\mathrm{T}$ cell medium. Subcutaneous $\mathrm{T}$ cell injections in both shoulders was performed over a 30-s period using a 28.5-gauge needle/syringe (2-3 mm lateral from the scapula).

Eight groups of mice were studied, 1 for each reporter system (8 reporter gene-radiolabeled probe combinations): $h N E T /{ }^{18} \mathrm{~F}-\mathrm{MFBG}$, $h d C K D M /{ }^{18} \mathrm{~F}-\mathrm{FEAU}, h s v T K /{ }^{18} \mathrm{~F}-\mathrm{FEAU}$ (groups $1-3$ ); $h N E T /{ }^{124} \mathrm{I}-\mathrm{MIBG}$; $h N I S /{ }^{124} \mathrm{I}$-iodide, $h d C K D M /{ }^{124} \mathrm{I}-\mathrm{FIAU}$, and $h s v T K /{ }^{124} \mathrm{I}$-FIAU (groups 4-7); and $h N E T /^{123}$ I-MIBG (group 8). Four cohorts of animals, injected with different numbers of $\mathrm{T}$ cells, were studied for each of the reporter gene-radiolabeled probe combinations, except for $h N E T /{ }^{123} \mathrm{I}-\mathrm{MIBG}$ (group 8) for which 4 cohorts were analyzed. Animals in cohort A of groups 1-7 ( $n=8$ animals/reporter system) received a subcutaneous injection of reporter-transduced T cells $\left(10^{5}\right.$ and $\left.10^{6}\right)$ in opposite shoulders. Animals in cohort B of groups $1-7(n=8$ animals/reporter system) received a subcutaneous injection of reporter-transduced T cells $\left(3 \times 10^{5}\right.$ and $\left.3 \times 10^{6}\right)$ in opposite shoulders. Mice in group $8\left({ }^{123} \mathrm{I}-\mathrm{MIBG} / \mathrm{hNET}\right.$; $n=17)$ were divided into 3 cohorts: cohort $\mathrm{A}\left(10^{5}\right.$ and $10^{6} \mathrm{~T}$ cells $)$, cohort $\mathrm{B}\left(3 \times 10^{5}\right.$ and $3 \times 10^{6} \mathrm{~T}$ cells $)$, and cohort $\mathrm{C}\left(10^{7}\right.$ and $3 \times 10^{7}$ $\mathrm{T}$ cells). Thirty minutes after $\mathrm{T}$ cell injection, animals received an intravenous injection of the appropriate/corresponding radiolabeled probe.

\section{Nuclear Imaging of Primary T Cells}

Animals from the $h N E T /{ }^{18} \mathrm{~F}-\mathrm{MFBG}, \quad h s v T K /{ }^{18} \mathrm{~F}-\mathrm{FEAU}$, and $h d C K D M /{ }^{18} \mathrm{~F}-\mathrm{FEAU}$ groups (1-3) were injected with $7.4 \mathrm{MBq}$ $(200 \mu \mathrm{Ci})$ of radiolabeled probe, respectively, and imaged 2 and $4 \mathrm{~h}$ after tracer administration. Animals from the $h N E T /{ }^{124} \mathrm{I}-\mathrm{MIBG}, h N I S /{ }^{124} \mathrm{I}-$ iodide, $h d C K D M /{ }^{124} \mathrm{I}$-FIAU, and $h s v T K /{ }^{124} \mathrm{I}$-FIAU groups (4-7) were injected with $14.8 \mathrm{MBq}(400 \mu \mathrm{Ci})$ of radiolabeled probe, respectively, and imaged 4 and $24 \mathrm{~h}$ after administration. Animals from the $h N E T /{ }^{123}$ I-MIBG group (8) were injected with $29.6 \mathrm{MBq}(800 \mu \mathrm{Ci})$ of ${ }^{123} \mathrm{I}-\mathrm{MIBG}$ and imaged 4 and $24 \mathrm{~h}$ after administration. PET imaging was performed using a Focus 120 microPET scanner (Siemens Medical Solutions USA, Inc.). A narrow energy window of 420-580 keV and a coincidence timing window of $6 \mathrm{~ns}$ were used for ${ }^{124} \mathrm{I}$-labeled probes, and a wide 350 - to $750-\mathrm{keV}$ window was used for ${ }^{18} \mathrm{~F}$-labeled probe. The image data were corrected for nonuniformity of scanner response, dead time count losses, and physical decay to the time of injection. No correction was applied for attenuation, scatter, or partial-volume averaging.

Region-of-interest analysis of the acquired images was performed using ASIPro software (Siemens Medical Solutions USA, Inc.); total radioactivity and the maximum pixel values were recorded for each $\mathrm{T}$ cell injection site. Iodide uptake in the thyroid and stomach was not blocked, and radioactivity in these organs reflects radioactive iodide release after the slow catabolism of ${ }^{124}$ I-MIBG. Because of the rapid uptake and washout/clearance of free ${ }^{124} \mathrm{I}$-iodide, multiple imaging time points $(0.5,1,2,4$, and $24 \mathrm{~h})$ were obtained for the $h N I S /{ }^{124} \mathrm{I}$ iodide reporter $\mathrm{T}$ cell-bearing animals.

SPECT imaging was performed on each animal receiving ${ }^{123} \mathrm{I}-$ MIBG using a nano-SPECT/CT dedicated small-animal scanner (Bioscan Inc. USA). A photo peak energy window of $143-175 \mathrm{keV}$ and a low-energy, high-resolution collimator were used to acquire the ${ }^{123} \mathrm{I}$ images. Transverse images were reconstructed by filtered backprojection. Quantification was performed using InVivoScope Integrated proprietary Bioscan Analysis Software.

\section{Statistics}

The statistical significance of differences between mean values was estimated with Excel (Microsoft) using the independent $t$ test for unequal variances. $P$ values of less than 0.05 were considered to be statistically significant. 


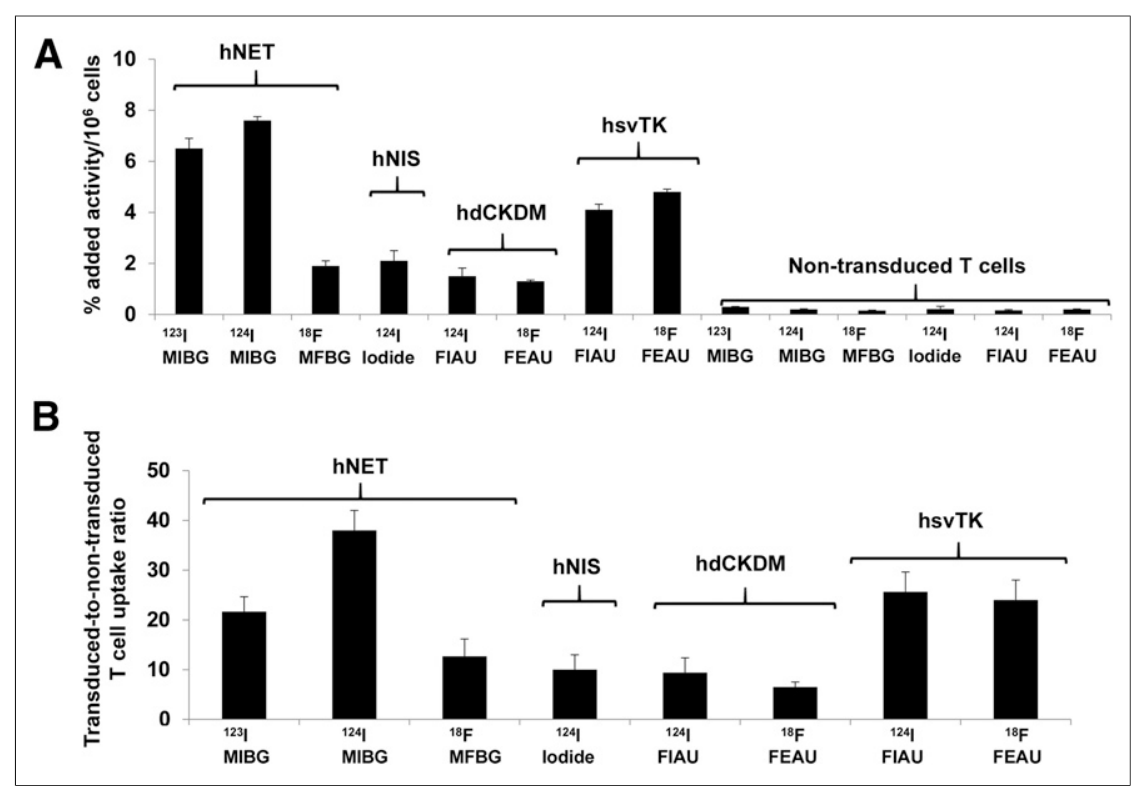

FIGURE 1. In vitro uptake of radiolabeled probes in human T cells transduced with different reporters. Data are presented as percentage added radioactivity $/ 10^{6}$ reporter-transduced $T$ cells (A) and as transduced-to-nontransduced $T$ cell uptake ratios (B). Data are presented from 3 independent experiments.

\section{RESULTS}

\section{Characterization of Reporter Gene-Transduced Primary} Human T Cells

After transduction, reporter-bearing primary human $\mathrm{T}$ cells were characterized for viability and reporter expression. Fluorescenceactivated cell sorting profiles demonstrated a high fraction of viable and GFP-positive reporter cells. Each transduction yielded a high percentage of GFP-positive cells: $77.8 \%$ for hNET/GFP, $72.4 \%$ for hNIS/GFP, $83.4 \%$ for human hdCKDM/GFP, and 77.6\% for hsvTK/ GFP-transduced $\mathrm{T}$ cells, respectively, and high mean fluorescence levels corresponding to the respective vector design. All primary $\mathrm{T}$ cell groups demonstrated the same rate of proliferation as wild-type cells and high viability $(>85 \%)$ (Supplemental Fig. 3).

\section{In Vitro Reporter-Transduced Human T Cell Uptake Studies}

The initial assessment and comparison of the 4 reporter systems in human $\mathrm{T}$ cells was performed in vitro using a radiolabeled probe uptake assay (Fig. 1). The highest uptake levels were obtained with ${ }^{123} \mathrm{I}-\mathrm{MIBG}$ and ${ }^{124} \mathrm{I}-\mathrm{MIBG}$ in hNET reporter-bearing $\mathrm{T}$ cells after $2 \mathrm{~h}$ of incubation $(6.5 \pm 0.4$ and $7.6 \% \pm 0.1 \%$ of added radioactivity per $10^{6}$ cells, respectively). Similarly, the hNETtransduced-to-nontransduced $\mathrm{T}$ cell ratios were also high. These values were significantly higher than those obtained with ${ }^{18} \mathrm{~F}$ MFBG $\left(1.9 \% \pm 0.2 \%\right.$ per $10^{6}$ cells $)$, which is consistent with prior in vitro uptake studies comparing MIBG and MFBG uptake in hNET-expressing tumor cells $(15,25)$. Comparable values were measured in hNIS $\left(2.2 \% \pm 0.9 \%\right.$ per $10^{6}$ cells $)$, hsvTK $\left(4.1 \% \pm 0.41 \%\right.$ per $10^{6}$ cells), and hdCKDM $(1.5 \% \pm 0.25 \%$ per $10^{6}$ cells) reporter-bearing $\mathrm{T}$ cells with ${ }^{124} \mathrm{I}$-iodide, ${ }^{18} \mathrm{~F}-\mathrm{FEAU}$, and ${ }^{124}$ I-FIAU, respectively.

\section{In Vivo Imaging of Reporter-Transduced Human T Cells in Athymic Mice}

A comparison of the hNET and hNIS reporter systems is shown in Figures 2 and 3. Prior studies have shown that ${ }^{18} \mathrm{~F}-\mathrm{MFBG}$ and ${ }^{124}$ I-MIBG accumulation in hNET-expressing tumor cells is stable between 2 and $4 \mathrm{~h}$ after injection $(15,25)$, whereas ${ }^{124}$ I-iodide accumulation peaks at approximately $1 \mathrm{~h}$ and then washes out of hNISexpressing cells and tumors $(13,29,30)$. Thus, imaging was performed more frequently in the $h N I S /{ }^{124} \mathrm{I}$-iodide experiments. Although the high background of ${ }^{124} \mathrm{I}-\mathrm{MIBG}$ at early $(4 \mathrm{~h})$ time points prevented the detection of individual signals from $\mathrm{T}$ cell injection sites, the long $(\sim 4 \mathrm{~d})$ half-life of ${ }^{124} \mathrm{I}-\mathrm{MIBG}$ allowed for late $(24 \mathrm{~h})$ imaging. Although the maximum accumulation of ${ }^{18} \mathrm{~F}-\mathrm{MFBG}$ and ${ }^{124} \mathrm{I}$-iodide radioactivity by the subcutaneously injected reporter-bearing $\mathrm{T}$ cells was similar, the contrast ( $\mathrm{T}$ cell-tobackground radioactivity ratio) was significantly higher for the $h N E T /{ }^{18} \mathrm{~F}-\mathrm{MFBG}$ reporter system $(\sim 14 / 1$ at $4 \mathrm{~h})$ than for $h N E T /{ }^{124} \mathrm{I}-\mathrm{MIBG}$ reporter $(\sim 7 / 1$ at $24 \mathrm{~h})$ and $h N I S /{ }^{124} \mathrm{I}$-iodide reporter $(\sim 3 / 1$ at 1-4 h) for the highest $\mathrm{T}$ cell-injected number $\left(3 \times 10^{6}\right)$. Because of the lower background, the $h N E T /{ }^{18} \mathrm{~F}-\mathrm{MFBG}$ reporter was able to detect less than $10^{5} \mathrm{~T}$ cells, compared with approximately $10^{6} \mathrm{~T}$ cells for the $h N I S /{ }^{124}$ I-iodide and $h N E T /{ }^{124} \mathrm{I}$ MIBG reporter (Table 1). The SPECT studies of $h N E T /^{123} \mathrm{I}-\mathrm{MIBG} \mathrm{T}$ cell imaging
FIGURE 2. PET imaging of human primary $T$ cells transduced with $h N E T(A)$ or $h N I S(B)$ reporters. Different numbers of $T$ cells were injected subcutaneously, followed by systemic administration of corresponding radiopharmaceuticals and PET imaging at respective time points. Number of T cells injected is shown in right upper and lower panels. $\% \mathrm{ID} / \mathrm{g}=$ percentage injected dose per gram.

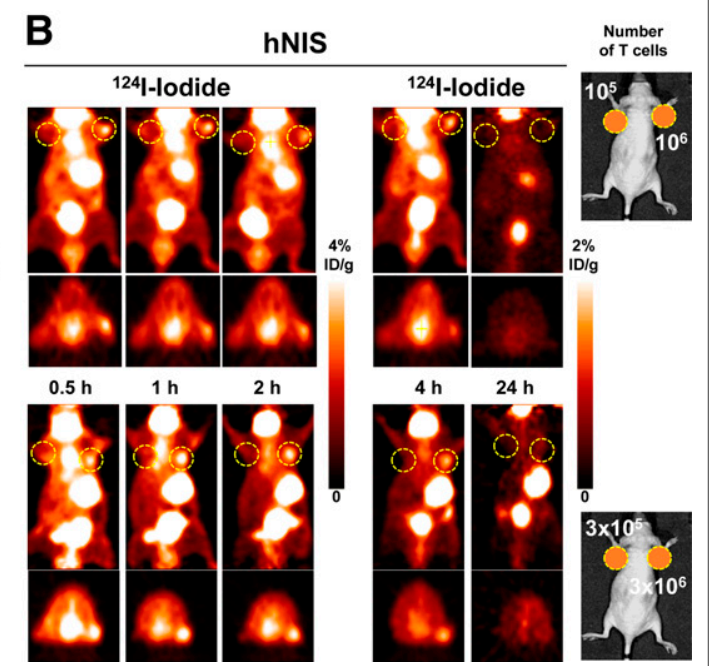

T Cell Imaging with Human Reporter Genes • Moroz et al. 


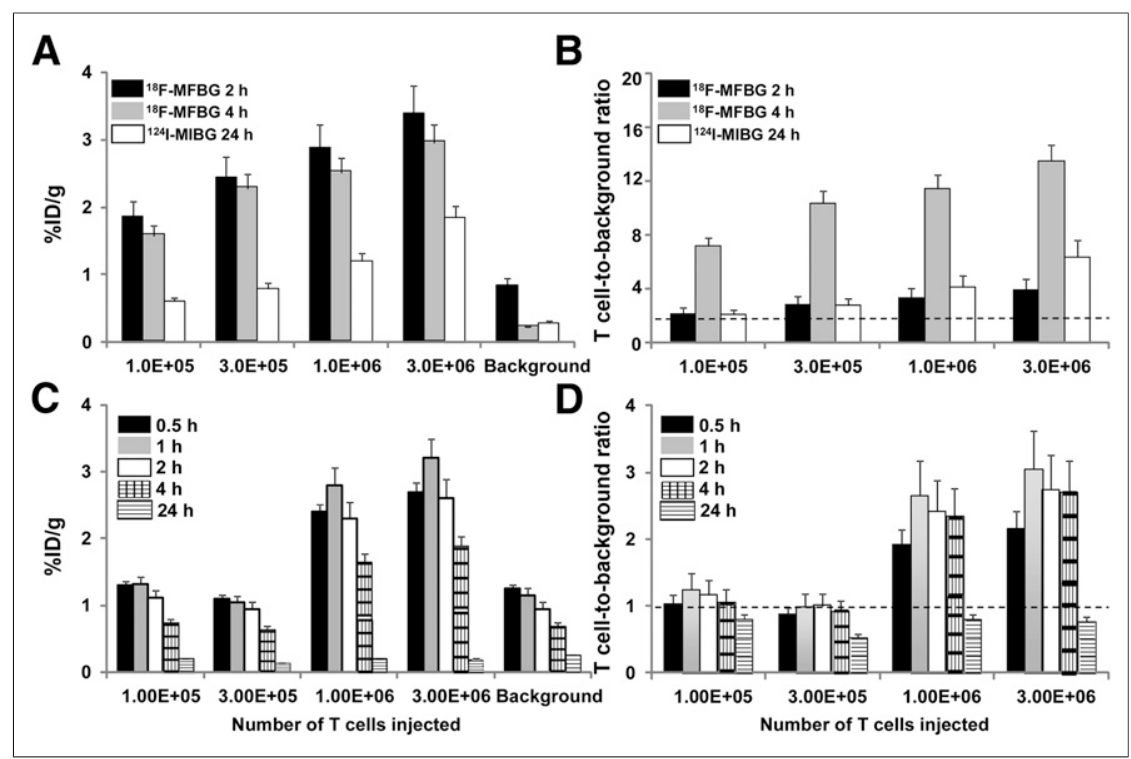

FIGURE 3. Analysis of PET images of human T cells transduced with hNET (A and B) and hNIS ( $C$ and $D)$ reporters, as shown in Figure 2. Data are \%ID/g \pm SD ( $A$ and $C$ ) and T cell-to-background ratios $\pm S D(B$ and $D)$. Data are from 2 independent experiments. $\% \mathrm{ID} / \mathrm{g}=$ percentage injected dose per gram.

failed to visualize $3 \times 10^{6}$ cells. Therefore, ultrahigh numbers $\left(10^{7}\right.$ and $\left.3 \times 10^{7}\right)$ of hNET reporter T cells were injected, followed by $29.6 \mathrm{MBq}(800 \mu \mathrm{Ci})$ of ${ }^{123} \mathrm{I}-\mathrm{MIBG}$ and SPECT imaging at 4 and $24 \mathrm{~h}$. The results of this additional study demonstrated a clear signal at the injection site of $3 \times 10^{7} \mathrm{hNET}$ reporter T cells but not at the $10^{7} \mathrm{~T}$ cell injection site (Supplemental Fig. 4).

The $\mathrm{T}$ cell imaging patterns observed with the hdCKDM/GFP and herpes simplex virus hsvTK/GFP fusion reporters with either ${ }^{18} \mathrm{~F}$ FEAU or ${ }^{124}$ I-FIAU were similar and between those observed with the $h N E T /{ }^{18} \mathrm{~F}-\mathrm{MFBG}$ and hNIS/ ${ }^{124} \mathrm{I}$-iodide reporter systems (Figs. 4 and 5). Because both reporter systems have been shown previously to result in fairly stable radioactivity accumulation in tumor cells between 1 and $4 \mathrm{~h}$ after injection of tracer $(11,12,24)$, we studied only the 4-h time point to allow for optimal clearance of ${ }^{18} \mathrm{~F}-\mathrm{FEAU}$ and ${ }^{124}$ I-FIAU background radioactivity. ${ }^{18} \mathrm{~F}$-FEAU yielded significantly higher $\mathrm{T}$ cell accumulation values than ${ }^{124} \mathrm{I}$-FIAU at $4 \mathrm{~h}$ for both reporters, and the T cell-to-background ratios with ${ }^{18} \mathrm{~F}-\mathrm{FEAU}$ were higher than with ${ }^{124}$ I-FIAU, partly due to the lower background values observed with ${ }^{18} \mathrm{~F}$-FEAU. Both $h d C K D M /{ }^{18} \mathrm{~F}-\mathrm{FEAU}$ and the $h s v T K /{ }^{18} \mathrm{~F}-\mathrm{FEAU}$ reporter systems were able to detect approximately $3 \times 10^{5} \mathrm{~T}$ cells at $4 \mathrm{~h}$ (Fig. 5 ; Table 1 ).

\section{DISCUSSION}

The objective of this report was to determine the minimum number of $\mathrm{T}$ cells that can be imaged by different reporter systems (reporter gene + radiolabeled probe) using PET in a murine model. Three human genes (hNET, hNIS, and hdCKDM) and an established viral reporter gene (hsvTK), coupled with their corresponding radiolabeled substrates (comprising different reporter systems), were studied. We compared the sensitivity of the reporter systems to image different numbers of hNET-, hNIS-, hdCKDM-, and hsvTKtransduced T cells at subcutaneous injection sites. All PET reporter systems were effective, but there was a greater than 10-fold difference in threshold sensitivity for $\mathrm{T}$ cell detection (Table 1). Not surprisingly, the SPECT reporter system ( $\left.h N E T /^{123} \mathrm{I}-\mathrm{MIBG}\right)$ had more than 100-fold-lower sensitivity than the most sensitive PET reporter system ( $\left.h N E T /{ }^{18} \mathrm{~F}-\mathrm{MFBG}\right)$. The $h N E T /{ }^{18} \mathrm{~F}-\mathrm{MFBG}$ reporter system could detect less than $1 \times$ $10^{5} \mathrm{~T}$ cells, and we were able to visualize all 4 sets of $\mathrm{T}$ cells (ranging in number between $1 \times 10^{5}$ and $3 \times 10^{6}$ ) in all experimental animals ( $n=8$ per group). The equation describing the relationship between $\mathrm{T}$ cell number and measured radioactivity above background levels is $\mathrm{T}$ cell number at the injection site $=31,515 \times \mathrm{e}^{(1.03 \times[\text { measured }}$ percentage injected radioactivity/g - background]) $(R=$ 0.80). Thus, approximately $35,000-40,000$ hNET reporter T cells can be detected using ${ }^{18} \mathrm{~F}-\mathrm{MFBG}$ and small-animal PET, $4 \mathrm{~h}$ after their subcutaneous injection and intravenous administration of the radiotracer.

This study builds on a recent comparison between ${ }^{18} \mathrm{~F}-\mathrm{MFBG}$ and clinically approved ${ }^{123} /{ }^{124}$ I-MIBG for imaging of hNET-expressing cells and tumors $(15,25)$. These studies showed that ${ }^{18} \mathrm{~F}-\mathrm{MFBG}$ can be synthesized in reasonable radiochemical yields under milder conditions and that it is a more hydrophilic benzylguanidine analog than MIBG, has a lower binding to plasma proteins, and is cleared more rapidly from nontarget tissues and from the body. These characteristics result in superior tumor-to-background images at earlier times after administration of MFBG, compared with MIBG. Although the in vitro experimental data (Fig. 1) and the previously published binding data (15) suggest that MIBG would be a more effective probe than MFBG, the higher $\log \mathrm{D}$ and serum protein binding and slower body clearance of MIBG, compared with that of MFBG, account for the discordance between the in vitro and in vivo uptake results. These results also corroborate previously published studies using the hNET reporter system in a model of intratumorally injected Epstein-Barr virus-specific T cells (30).

hNIS imaging, after administration of ${ }^{124}$ I-iodide, demonstrated rapid accumulation and rapid clearance of the probe from the sites of $\mathrm{T}$ cell injection, which is similar to the results described by us and others $(29,31)$ in stably transduced xenografts. However, the T cell-to-background ratio was fairly stable from 1 to $4 \mathrm{~h}$ due to the rapid clearance of iodide from most tissues (background) as well as

TABLE 1

Sensitivity of T Cell Number-Dependent Reporter Imaging Using PET

\begin{tabular}{|c|c|}
\hline Reporter system & Sensitivity \\
\hline $\mathrm{hNET} /{ }^{18} \mathrm{~F}-\mathrm{MFBG}$ at $4 \mathrm{~h}$ & $<1 \times 10^{5} \mathrm{~T}$ cells \\
\hline $\mathrm{dCK} /{ }^{18} \mathrm{~F}-\mathrm{FEAU}$ at $4 \mathrm{~h}$ & $\sim 3 \times 10^{5} \mathrm{~T}$ cells \\
\hline $\mathrm{hsvTK} /{ }^{18} \mathrm{~F}-\mathrm{FEAU}$ at $4 \mathrm{~h}$ & $\sim 3 \times 10^{5} \mathrm{~T}$ cells \\
\hline $\mathrm{hNET} /{ }^{18} \mathrm{~F}-\mathrm{MFBG}$ at $2 \mathrm{~h}$ & $\sim 1 \times 10^{6} \mathrm{~T}$ cells \\
\hline hNET/124I-MIBG at $24 \mathrm{~h}$ & $\sim 1 \times 10^{6} \mathrm{~T}$ cells \\
\hline $\mathrm{hNIS} /{ }^{124} \mathrm{I}$-iodide at $1 \mathrm{~h}$ & $\sim 1 \times 10^{6} \mathrm{~T}$ cells \\
\hline $\mathrm{dCK} /{ }^{124} \mathrm{I}-\mathrm{FIAU}$ at $4 \mathrm{~h}$ & $\sim 3 \times 10^{6} \mathrm{~T}$ cells \\
\hline hsvTK/ ${ }^{124} \mathrm{I}-\mathrm{FIAU}$ at $4 \mathrm{~h}$ & $\sim 3 \times 10^{6} \mathrm{~T}$ cells \\
\hline
\end{tabular}




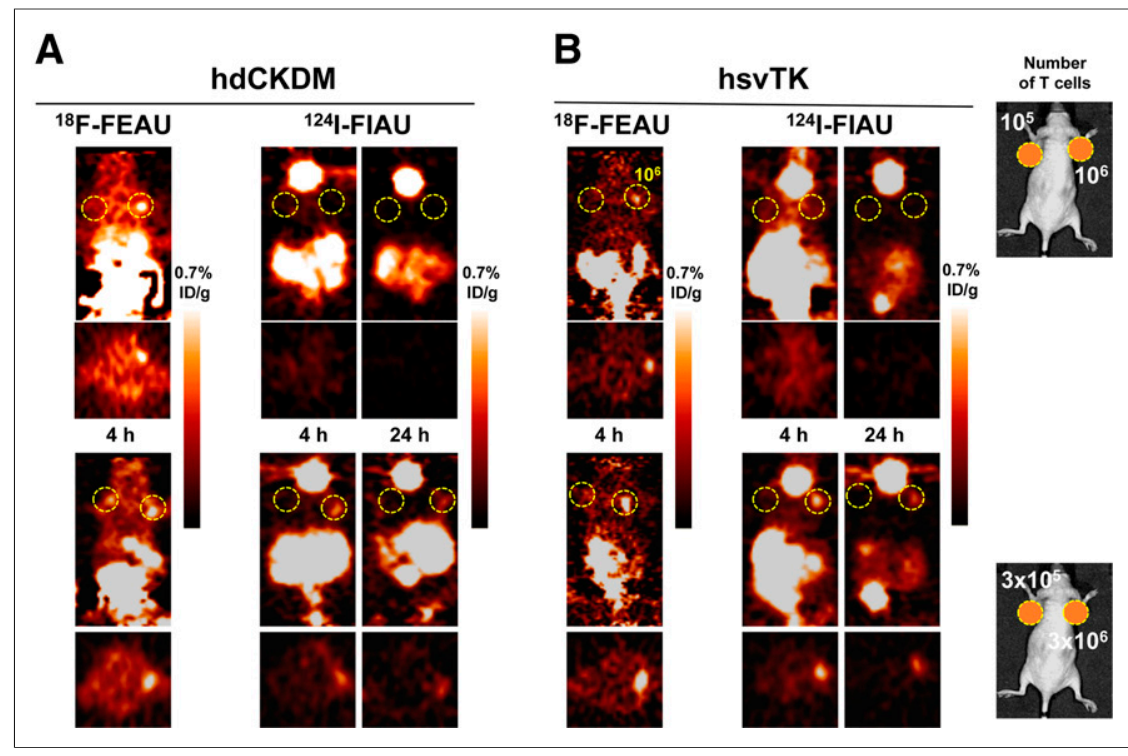

FIGURE 4. PET imaging of human primary $T$ cells transduced with hdCKDM (A) or hsvTK (B) reporters. Different numbers of T cells were injected subcutaneously, followed by systemic administration of corresponding radiopharmaceuticals and PET imaging at respective time points. Number of $\mathrm{T}$ cells injected is shown in right upper and lower panels. $\% \mathrm{ID} / \mathrm{g}=$ percentage injected dose per gram.

from the $\mathrm{T}$ cell injection site. The advantage of rapid initial accumulation was negated by the high background level of radioactivity and near-parallel clearance from the $\mathrm{T}$ cell injection site and surrounding tissues (background).

PET imaging of hsvTK/GFP and hdCKDM/GFP with ${ }^{18} \mathrm{~F}-\mathrm{FEAU}$ also yielded positive results for $\mathrm{T}$ cell numbers between $3 \times 10^{5}$ and 3 $\times 10^{6}$. Similar PET T cell imaging threshold values were obtained with $h s v T K s r 39 /{ }^{18}$ F-FHBG by Su et al. and Yaghoubi et al. $(32,33)$. HsvTK and human dCKDM reporter imaging with ${ }^{124}$ I-FIAU and PET at $24 \mathrm{~h}$ after injection was only able to reliably visualize the highest number of $\mathrm{T}$ cells injected $\left(3 \times 10^{6}\right)$. Only $20 \%$ of the

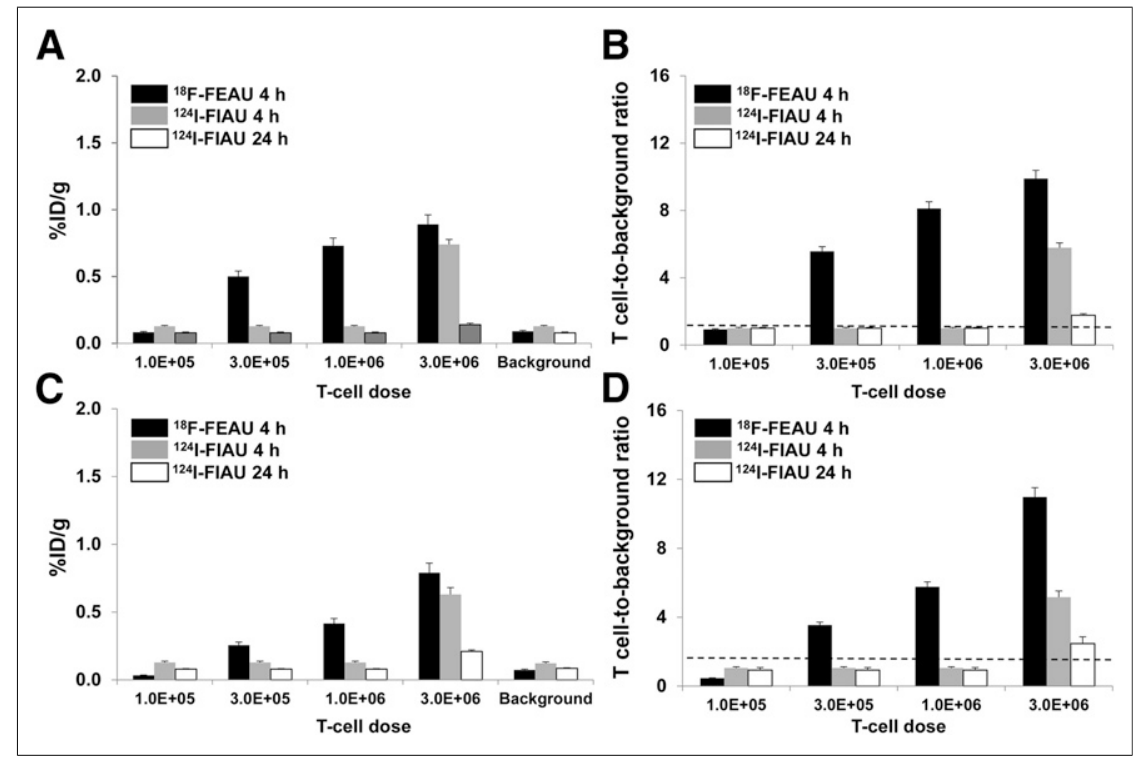

FIGURE 5. Analysis of PET images of human $T$ cells transduced with hdCKDM ( $A$ and $B)$ and hsvTK $(C$ and $D)$, as shown in Figure 4 . Data are $\% \mathrm{ID} / \mathrm{g} \pm \mathrm{SD}(\mathrm{A}$ and $\mathrm{C})$ and T cell-to-background ratios to \pm $\mathrm{SD}(\mathrm{B}$ and $\mathrm{D})$. Data are from 2 independent experiments. \%ID/g = percentage injected dose per gram. animals showed a positive $\mathrm{T}$ cell signal after injection of $1 \times 10^{6}$ cells, and no visualization of T cells was observed below $1 \times 10^{6} \mathrm{~T}$ cells by either hsvTK or hdCKDM imaged with ${ }^{124}$ I-FIAU.

We and others have previously demonstrated that FEAU has more rapid body clearance, lower background, and higher affinity to and accumulation by HsvTK and hdCKDM enzymes than FIAU (12). These preferential pharmacokinetic and pharmacodynamic parameters resulted in a lower $\mathrm{T}$ cell detection threshold with ${ }^{18} \mathrm{~F}$-FEAU than with ${ }^{124}$ I-FIAU.

The in vivo experiments demonstrated an advantage of short-half-life ${ }^{18} \mathrm{~F}$-based probes that clear nontarget tissue and the body rapidly, including ${ }^{18} \mathrm{~F}-\mathrm{MFBG}$ and ${ }^{18} \mathrm{~F}-\mathrm{FEAU}$ for imaging early (i.e., $4 \mathrm{~h}$ ). In contrast, the more slowly clearing iodine-based substrates, such as ${ }^{124} \mathrm{I}-\mathrm{MIBG},{ }^{123} \mathrm{I}-\mathrm{MIBG}$, and ${ }^{124} \mathrm{I}-\mathrm{FIAU}$, require a longer time to achieve a good target-to-background ratio because the bulky electron-donor iodine is more hydrophobic than the small electron-acceptor fluorine. The $h N E T /{ }^{123} \mathrm{I}-\mathrm{MIBG}$ SPECT study showed the lowest sensitivity, with no visualization of $3 \times 10^{6} \mathrm{~T}$ cells at both early $(2-4 \mathrm{~h})$ and late $(8-24 \mathrm{~h})$ time points after subcutaneous injection. An additional $h N E T /^{123}$ I-MIBG study, with injection of high numbers of T cells $\left(1 \times 10^{7}\right.$ and $\left.3 \times 10^{7}\right)$, showed reliable detection of T cells only at the highest number injected, demonstrating the limitation of ${ }^{123}$ I-MIBG SPECT imaging.

\section{CONCLUSION}

A comparison of different constitutively expressed radionuclidebased reporter genes ( 3 human and 1 viral) and their corresponding reporter probes for imaging of $\mathrm{T}$ cell number was performed. The $h N E T /{ }^{18} \mathrm{~F}-\mathrm{MFBG}$ PET reporter system was the most sensitive, capable of detecting $3-4 \times 10^{4} \mathrm{~T}$ cells at the site of $\mathrm{T}$ cell injection in the animal model. Fast-clearing short-half-life ${ }^{18} \mathrm{~F}$-based probes demonstrate high specificity and allow for repetitive of $\mathrm{T}$ cell imaging.

\section{DISCLOSURE}

The costs of publication of this article were defrayed in part by the payment of page charges. Therefore, and solely to indicate this fact, this article is hereby marked "advertisement" in accordance with 18 USC section 1734. This work was supported by the NIH P50 CA86438-11, R01 CA163980, and R01 CA161138 grants and Mr. William H. Goodwin and Mrs. Alice Goodwin and the Commonwealth Foundation for Cancer Research and The Experimental Therapeutics Center of Memorial Sloan Kettering Cancer Center. Technical services were provided by the MSKCC Small-Animal Imaging Core Facility, 
supported in part by NIH Small-Animal Imaging Research Program (SAIRP), NIH Shared Instrumentation grant no. 1 S10 RR020892-01, NIH Shared Instrumentation grant no. 1 S10 RR028889-01, and NIH Center grant P30 CA08748. No other potential conflict of interest relevant to this article was reported.

\section{ACKNOWLEDGMENTS}

We thank Dr. Jason Lewis and the Radiochemistry Core for their technical assistance and expertise.

\section{REFERENCES}

1. Koehne G, Doubrovin M, Doubrovina E, et al. Serial in vivo imaging of the targeted migration of human HSV-TK-transduced antigen-specific lymphocytes. Nat Biotechnol. 2003;21:405-413.

2. Su H, Chang DS, Gambhir SS, Braun J. Monitoring the antitumor response of naive and memory CD8 T cells in RAG1 - / - mice by positron-emission tomography. J Immunol. 2006;176:4459-4467.

3. Dubey P, Su H, Adonai N, et al. Quantitative imaging of the T cell antitumor response by positron-emission tomography. Proc Natl Acad Sci USA. 2003;100: 1232-1237.

4. Dobrenkov K, Olszewska M, Likar Y, et al. Monitoring the efficacy of adoptively transferred prostate cancer-targeted human T lymphocytes with PET and bioluminescence imaging. J Nucl Med. 2008;49:1162-1170.

5. Choi SR, Zhuang ZP, Chacko AM, et al. SPECT imaging of herpes simplex virus type1 thymidine kinase gene expression by ${ }^{123}$ I-FIAU(1). Acad Radiol. 2005;12: 798-805.

6. Zinn KR, Chaudhuri TR, Krasnykh VN, et al. Gamma camera dual imaging with a somatostatin receptor and thymidine kinase after gene transfer with a bicistronic adenovirus in mice. Radiology. 2002;223:417-425.

7. Zinn K, Chaudhuri TR, Krasnykh VN, et al. Molecular imaging of temporal dynamics and thymidine kinase after gene transfer with a bicistronic adenovirus in mice. Radiology. 2004;64:417-425.

8. Serganova I, Doubrovin M, Iyer M, et al. Molecular imaging of temporal dynamics and spatial heterogeneity of hypoxia-inducible factor-1 signal transduction activity in tumors in living mice. Cancer Res. 2004;64:6101-6108.

9. Yaghoubi S, Barrio JR, Dahlbom M, et al. Human pharmacokinetic and dosimetry studies of $\left[{ }^{18} \mathrm{~F}\right] \mathrm{FHBG}$ : a reporter probe for imaging herpes simplex virus type-1 thymidine kinase reporter gene expression. J Nucl Med. 2001;42:1225-1234.

10. Min JJ, Iyer M, Gambhir SS. Comparison of ${ }^{18} \mathrm{~F}-\mathrm{FHBG}$ and ${ }^{14} \mathrm{C}-\mathrm{FIAU}$ for imaging of HSV1-tk reporter gene expression: adenoviral infection vs stable transfection. Eur J Nucl Med Mol Imaging. 2003;30:1547-1560.

11. Tjuvajev JG, Doubrovin M, Akhurst T, et al. Comparison of radiolabeled nucleoside probes (FIAU, FHBG, and FHPG) for PET imaging of HSV1-tk gene expression. J Nucl Med. 2002;43:1072-1083.

12. Miyagawa T, Gogiberidze G, Serganova I, et al. Imaging of HSV-tk Reporter gene expression: comparison between ${ }^{18} \mathrm{~F}-\mathrm{FEAU},{ }^{18} \mathrm{~F}-\mathrm{FFEAU}$, and other imaging probes. J Nucl Med. 2008;49:637-648.

13. Che J, Doubrovin M, Serganova I, et al. hNIS-IRES-eGFP dual reporter gene imaging. Mol Imaging. 2005;4:128-136.

14. Moroz MA, Serganova I, Zanzonico P, et al. Imaging hNET reporter gene expression with ${ }^{124}$ I-MIBG. $J$ Nucl Med. 2007;48:827-836.
15. Zhang H, Huang R, Pillarsetty N, et al. Synthesis and evaluation of ${ }^{18}$ F-labeled benzylguanidine analogs for targeting the human norepinephrine transporter. Eur J Nucl Med Mol Imaging. 2014;41:322-332.

16. Reubi JC, Kvols L, Krenning E, et al. Distribution of somatostatin receptors in normal and tumor tissue. Metabolism. 1990;39:78-81.

17. Zhang H, Moroz MA, Serganova I, et al. Imaging expression of the human somatostatin receptor subtype-2 reporter gene with ${ }^{68} \mathrm{Ga}$-DOTATOC. $\mathrm{J} \mathrm{Nucl}$ Med. 2011;52:123-131.

18. Genove $\mathrm{G}$, DeMarco $\mathrm{U}, \mathrm{Xu} \mathrm{H}$, et al. A new transgene reporter for in vivo magnetic resonance imaging. Nat Med. 2005;11:450-454.

19. Moore A, Josephson L, Bhorade RM, et al. Human transferrin receptor gene as a marker gene for MR imaging. Radiology. 2001;221:244-250.

20. Campbell DO, Yaghoubi SS, Su Y, et al. Structure-guided engineering of human thymidine kinase 2 as a positron emission tomography reporter gene for enhanced phosphorylation of non-natural thymidine analog reporter probe. $J$ Biol Chem. 2012;287:446-454.

21. Ponomarev V, Doubrovin M, Shavrin A, et al. A human-derived reporter gene for noninvasive imaging in humans: mitochondrial thymidine kinase type 2 . J Nucl Med. 2007;48:819-826.

22. Schwarzenberg J, Radu CG, Benz M, et al. Human biodistribution and radiation dosimetry of novel PET probes targeting the deoxyribonucleoside salvage pathway. Eur J Nucl Med Mol Imaging. 2011;38:711-721.

23. Murphy JM, Armijo AL, Nomme J, et al. Development of new deoxycytidine kinase inhibitors and noninvasive in vivo evaluation using positron emission tomography. J Med Chem. 2013;56:6696-6708.

24. Likar Y, Zurita J, Dobrenkov K, et al. A new pyrimidine-specific reporter gene: a mutated human deoxycytidine kinase suitable for PET during treatment with acycloguanosine-based cytotoxic drugs. J Nucl Med. 2010;51:1395-1403.

25. Zhang H, Huang R, Cheung NK, et al. Imaging the norepinephrine transporter in neuroblastoma: a comparison of ${ }^{18} \mathrm{~F}-\mathrm{MFBG}$ and ${ }^{123} \mathrm{I}-\mathrm{MIBG}$. Clin Cancer Res. 2014;20:2182-2191.

26. Ponomarev V, Doubrovin M, Serganova I, et al. Cytoplasmically retargeted HSV1-tk/GFP reporter gene mutants for optimization of noninvasive moleculargenetic imaging. Neoplasia. 2003;5:245-254.

27. Iwatani Y, Amino N, Mori H, et al. Effects of various isolation methods for human peripheral lymphocytes on $\mathrm{T}$ cell subsets determined in a fluorescence activated cell sorter (FACS), and demonstration of a sex difference of suppressor/ cytotoxic T cells. J Immunol Methods. 1982;54:31-42.

28. Zhang H, Cantorias MV, Pillarsetty N, et al. An improved strategy for the synthesis of $\left[{ }^{18} \mathrm{~F}\right]$-labeled arabinofuranosyl nucleosides. Nucl Med Biol. 2012;39: 1182-1188.

29. Miyagawa M, Anton M, Wagner B, et al. Non-invasive imaging of cardiac transgene expression with PET: comparison of the human sodium/iodide symporter gene and HSV1-tk as the reporter gene. Eur J Nucl Med Mol Imaging. 2005;32: 1108-1114.

30. Doubrovin MM, Doubrovina ES, Zanzonico P, et al. In vivo imaging and quantitation of adoptively transferred human antigen-specific $\mathrm{T}$ cells transduced to express a human norepinephrine transporter gene. Cancer Res. 2007;67:1195911969.

31. Miyagawa M, Beyer M, Wagner B, et al. Cardiac reporter gene imaging using the human sodium/iodide symporter gene. Cardiovasc Res. 2005;65:195-202.

32. Yaghoubi SS, Gambhir SS. PET imaging of herpes simplex virus type 1 thymidine kinase (HSV1-tk) or mutant HSV1-sr39tk reporter gene expression in mice and humans using ${ }^{18}$ F-FHBG. Nat Protoc. 2006;1:3069-3075.

33. Su H, Forbes A, Gambhir SS, et al. Quantitation of cell number by a positron emission tomography reporter gene strategy. Mol Imaging Biol. 2004;6:139-148. 